\title{
UN BOSQUEJO DEL FEMINISMO/S PERUANO/S: LOS MÚLTIPLES DESAFÍOS
}

\author{
Violeta Barrientos Silva \\ Pontificia Universidad Católica del Perú \\ Fanni Muñoz Cabrejo \\ Pontificia Universidad Católica del Perú
}

\begin{abstract}
Resumen: El artículo muestra las apuestas del feminismo en el Perú desde sus inicios, a partir de la lucha por el sufragio femenino, y más adelante, en la posguerra, la puesta en escena del cuerpo femenino como núcleo de una nueva forma de pensar lo político. Se muestra que es un movimiento de mujeres de sectores medios que se gesta bajo iniciativa gubernamental y con poca presencia de las corrientes de pensamiento teórico feminista europeas. Por el contrario, fue un movimiento vinculado a ideologías de izquierda aunque, paradójicamente, sus propuestas no fueron acogidas por los partidos de izquierda. En el actual contexto de cambios que se operan en el Perú, a partir de la democratización del país y con una baja institucionalidad del Estado, los feminismos - sin una aparente organicidad - se enfrentan con varios desafíos, siendo el de la capacidad de responder a la heterogeneidad de los actores emergentes el más relevante.

Palabras clave: feminismo; movimiento feminista; institucionalidad; gobierno; democratización.
\end{abstract}

\section{Introducción'}

Este artículo plantea un esbozo del feminismo en el Perú desde su inicio en el siglo XX hasta hoy, identificando hilos conductores en esa trayectoria, como la relación con el Estado - si tecnocrática o politizada - en el contexto de una democracia dominada por regímenes resistentes a otorgar victorias políticas a los movimientos sociales y que negocian para sí el reconocimiento de las ciudadanías; y el desafío ante la heterogeneidad del movimiento de mujeres y sus distintas vertientes: la feminista, la de los sectores populares y

Copyright $\odot 2014$ by Revista Estudos Feministas.

'Agradecemos a Maruja Barrig, Virginia Vargas, Ana María Portugal, Roxanna Carrillo, por sus reflexiones para el desarrollo de este trabajo. A Karina Bidaseca, profesora de la UNSAM, quien posibilitó una fructífera interlocución a partir del Coloquio Internacional "Reconocer las superficies de nuestras hendiduras. Cartografiar el Sur de nuestros Feminismos, en julio de 2013. 
la relacionada con los espacios políticos. Un aspecto que también cabe destacar es que el feminismo peruano, al igual que lo que sucedió con otros países latinoamericanos, surgió vinculado al Estado.

El texto propone una lectura del feminismo/os en el Perú actual y los retos y perspectivas que afronta el movimiento. Este llega al siglo XXI sin remontar la crisis por la que atravesó durante la década de los noventa y la pendularidad que lo definió - entre la priorización de trabajar en el campo de las políticas públicas y la reivindicación por el reconocimiento de la igualdad de oportunidades - en análisis de Maruja Barrig. ${ }^{2}$ Los feminismos que se vienen configurando en el presente milenio, sin aparente organicidad y que constituyen un universo heterogéneo, son los que tienen que asumir la construcción de una agenda política distinta a la de las feministas institucionalizadas. El gran reto para los feminismos de la región, como anota Ana María Portugal, ${ }^{3}$ es consolidar los derechos y espacios ganados y contribuir con un nuevo lenguaje a la construcción de sociedades más justas y humanas.

Para la elaboración del presente artículo se han realizado cuatro entrevistas a reconocidas lideresas fundadoras y activistas del movimiento feminista peruano. Asimismo, se han revisado documentos y la bibliografía producida en este campo tanto en el Perú como en Latinoamérica.

\section{El reclamo de la cludadanía formal: derecho al sufragio (1911-1930)}

Un primer momento del feminismo fue aquel de la lucha por el reconocimiento de la igualdad jurídica de la mujer. Las mujeres hicieron su reclamo dentro de lo que sería el orden político convencional; exigieron, al menos, una ciudadanía formal. Las primeras feministas peruanas del siglo XX, con María Jesús Alvarado 4 a la cabeza, tuvieron como metas políticas el acceso a una educación igualitaria y el reconocimiento de su capacidad jurídica. También eran abanderadas de las causas de otros oprimidos como ellas, obreros e indígenas. Habría que decir que el feminismo que prosperó ideológicamente fue el de las mujeres de la clase alta y culta, rasgo que mantendría el feminismo más adelante. En el universo obrero, también las luchas sindicales estimulaban la aparición de actoras. La lucha de las mujeres, sin embargo, pudo conseguir, en 1933, el voto municipal en medio de los debates de la Asamblea Constituyente. Así, la Constitución de 1933 aprobó el sufragio para las mujeres peruanas mayores de edad (21 años), las casadas o que lo hubieran estado, y las madres de familia aunque no hubiesen llegado a su mayoría de edad. No se reconocía el que una mujer fuera trabajadora dependiente o independiente. Solo mantenerse en el statu quo de la familia y los hijos podían hacerla "mayor de edad".

El voto municipal, sin embargo, solo fue ejercido en 1963, pues ningún gobierno lo puso en práctica. El sufragio de las mujeres alfabetas en las elecciones presidenciales se aprobó en 1955 por el dictador Manuel Odría, mientras que el de los analfabetos/as recién llegaría en 1979. Así el voto de las mujeres fue el resultado de una maniobra política del mencionado dictador quien lo consideraba menos peligroso que el de las clases populares. Si bien las mujeres y asociaciones feministas venían luchando por conquistar sus derechos,

\footnotetext{
2 Maruja BARRIG, 1998

${ }^{3}$ Ana María PORTUGAL, entrevista julio de 2013.

${ }^{4}$ María Jesús Alvarado Rivera (1878-1971) es una de las primeras intelectuales feministas en Perú. Expresaba ideas a favor de la educación, libertad y autonomía de las mujeres. Luchó por conseguir el voto para las mujeres. Véase Margarita ZEGARRA, 2011
} 
la respuesta a sus reivindicaciones llegaba instrumentalizada por el gobierno; un patrón que sería recurrente a lo largo de la historia del movimiento como se analizará más adelante.

\section{El reclamo por una ciudadanía real desde el sujeto femenino (1973 - a nuestros días)}

Este período comprende una primera etapa de aparición del feminismo en los años setenta, caracterizada por expresiones callejeras de visibilidad, incomprensión de otros movimientos políticos y de sectores populares no identificados necesariamente con las causas de la mujer. Fue un lapso, sin embargo, acompañado hasta 1976 por las reformas democratizadoras del gobierno militar nacionalista de Velasco Alvarado y el apoyo de la cooperación internacional. Los ochenta serían además el contexto del conflicto armado interno, la violencia política y la crisis económica nacional. Los noventa, un momento de institucionalización de las demandas de igualdad al interior del Estado bajo el gobierno populista de Alberto Fujimori. Este último proceso habría de ser causa de tensión entre optar por una radicalización obviando al Estado, o negociar con él con riesgo de despolitización.

\section{La rebelión de las mujeres: la manifestación de sus cuerpos}

La rebelión de las mujeres desde su propia condición y colocando a su cuerpo como centro de reflexión habría de llegar cuando el feminismo empezó por revelar las relaciones de poder entre hombres y mujeres, y las puso en debate. En esta nueva forma de hacer política, la configuración de la categoría de "género" - construida en diálogo entre la academia y el movimiento feminista - constituyó un nuevo capítulo en la historia del movimiento.

El libro de Betty Friedan, La Mística de la Femineidad, de 1963, en el que se reeditaban las ideas del Segundo Sexo, influiría en líderes del movimiento, como Virginia Vargas ${ }^{5}$ y otras en esta nueva etapa. La obra de Simone de Beauvoir, si bien tuvo una resonancia a nivel más personal, no tuvo repercusión directa en el movimiento. Las primeras luchas de mujeres en relación a su condición tuvieron lugar entre los años 1970 y 1973 en Lima. Universitarias, trabajadoras sociales, integrantes de grupos de la iglesia progresista y/o antiguas militantes de partidos políticos salieron a las calles, y fue así como se dieron a conocer. Un hito durante este período lo constituyó la marcha de protesta del 8 de abril de 1973 contra el concurso de Miss Universo. La "rebelión de las brujas", como la prensa bautizó la protesta, significó el primer hito para la visibilización de las mujeres. ${ }^{6}$ La consigna de "tomar la calle", impregnó el trabajo de los primeros espacios feministas en la década del 70, y expresó a la sociedad el mensaje de que "lo privado es político y no intocable". Los concursos de belleza fueron suspendidos por el Ministerio de Educación acorde con la Ley General de Educación de 1972, ${ }^{7}$ que consideraba denigrante el que la mujer fuera usada como objeto sexual. Esta medida dura hasta el año 1976, en el que se desmantelan las iniciativas de dicha reforma progresista por la dictadura de Morales Bermúdez.

\footnotetext{
${ }^{5}$ Virginia Vargas Valente, socióloga y activista feminista. Es fundadora del Centro Flora Tristán. Asimismo, es miembro del Consejo Consultivo del Programa Democracia y Transformación Global.

${ }^{6}$ En esta marcha cerca de 100 mujeres con pancartas se instalaron frente al hotel Sheraton de la capital para manifestar su desacuerdo. La manifestación contra el concurso había sido convocada por ALIMUPER (Acción para la Liberación de la Mujer Peruana), primer grupo que se declaró feminista; por el grupo "Promoción de la Mujer", y por el Grupo de Trabajo "Flora Tristán" (otro distinto al CMP Flora Tristán, creado en 1979).

7 La Ley General de Educación, promulgada durante el régimen militar de Velasco Alvarado, promovió una reforma educativa según un marco nacionalista y democratizador de la sociedad. Esta reforma buscaba una transformación de la sociedad peruana.
} 
El segundo feminismo peruano del siglo XX toma fuerza gracias a la convergencia de dos factores políticos, uno interno - las reformas progresistas del gobierno militar peruano de Velasco Alvarado entre 1968 y 1976 - y otro externo, la realización de la Conferencia Mundial sobre la Mujer (1975), el Decenio de la Mujer (1975-1985) y el apoyo de la cooperación internacional a estas causas.

Sobre lo primero, habría que decir se presenta una confluencia entre la agenda del Estado respecto al posicionamiento de la mujer en la esfera pública y la respuesta a las demandas de participación pública de la mujer por parte del movimiento de mujeres. Es así que se crea el Consejo Nacional de Mujeres del Perú (1971), la Comisión Nacional de la Mujer Peruana-CONAMUP (1974) y el Comité Técnico de Revaloración de la Mujer - COTREM (1972) en el sector educación, que busca promover la coe-ducación y una educación no sexista, entre otros temas. ${ }^{8}$

En 1976, a resultas de un seminario académico dirigido a conocer la situación de las mujeres, y que se realiza con la ayuda de la cooperación internacional y el Estado a través del INC, se crea el Centro de la Mujer Peruana Flora Tristán. Resulta interesante el testimonio de Gina Vargas, al señalar el poco interés que mostró inicialmente cuando fue convocada para organizar el evento, pero fue este seminario el que cambió su mirada hacia las mujeres y su trayectoria personal. ${ }^{9}$

Más adelante, en mayo de 1978, se gestó el grupo de Manuela Ramos, ${ }^{10}$ que tuvo sus orígenes en ámbitos totalmente diferentes, al ser más bien un espacio en que confluyeron esposas de militantes del partido de izquierda, Vanguardia Revolucionaria. Manuela Ramos se inclinó a una reflexión desde las organizaciones populares; en esta postura se distanciaba de Flora Tristán, que optaba por una reflexión de todas las mujeres por el hecho de serlo. Desde Flora Tristán se dedicó recursos al desarrollo de las ideas, publicaciones y talleres literarios. Virginia Vargas, Maria Emma Mannarelli, Mariella Sala, Diana Miloslavic, entre otras, produjeron sendas publicaciones en sus respectivas áreas. Posteriormente, Flora Tristán impulsaría diplomados y una maestría de género en las universidades privadas y públicas del país, los que se desarrollaron a partir de 2001.

Esta situación planteó un primer debate entre quienes decían que el feminismo tenía que construirse en función a las organizaciones de mujeres de base, en un contexto de creciente crisis económica, inflación y surgimiento de movimientos populares; y quienes sostenían que había que tener una mirada abierta a todas las mujeres y sus problemas, y en particular, una reflexión radical desde el propio cuerpo.

El feminismo nació como un movimiento político destinado también a cambiar la vida de las mujeres y de su entorno más cercano, sus cuerpos, sus parejas y sus familias. Para esta nueva forma de hacer política, fue necesario generar grupos de autoconciencia al interior del movimiento de mujeres que modelaron los nuevos contenidos políticos. El feminismo perseguía una práctica política nueva que pedía un lugar para la mujer no solo en lo público, sino también en lo privado. La maternidad, el aborto, la sexualidad, la anticoncepción, la violencia contra las mujeres, así como la violación sexual, denunciaban cómo el poder de los hombres se ejercía sobre las mujeres. Uno de los temas difíciles de abordar era el del lesbianismo, lo que impulsó a algunas a formar el Grupo de Autoconciencia Lesbiana Feminista (GALF), que llegaría a tener veinte años de existencia.

\footnotetext{
${ }^{8}$ Fanni MUÑOZ et al., 2006, p. 73

${ }^{9}$ Entrevista del 14 de junio de 2013

${ }^{10}$ El Movimiento Manuela Ramos se constituye como organismo no gubernamental (ONG) con el nombre de Movimiento Manuela Ramos en agosto de 1980. Desde su creación, se aboca al trabajo con las organizaciones femeninas en zonas de bajos recursos, articulando el trabajo con los municipios y dirigentes vecinales.
} 
Para Maruja Barrig una de las pioneras del feminismo y fundadora del Movimiento Manuela Ramos, ser feminista era "una actitud visceral, que te salía de las entrañas. Era rebeldía, era búsqueda de otro tipo de parámetros en la vida, por lo menos eso fue mi caso."11

Para Barrig, la influencia de autoras como Elsa Chaney ${ }^{12}$ o Kate Young fue central en la construcción del pensamiento feminista. ${ }^{13}$ Barrig fue autora de los primeros textos que revelaban la realidad de las mujeres, convirtiéndose en el principal referente sobre este tema. Su obra "Cinturón de castidad. La mujer de clase media en el Perú" (1979) tuvo fuerte impacto en la sociedad limeña. A decir de Barrig, fueron las teóricas inglesas o norteamericanas (Firestone o Millet), más que las autoras españolas, francesas o italianas, las que influyeron en el feminismo peruano, interesado en resolver la situación social de las mujeres en el país.

\section{Los colectivos temáticos, la institucionalización de las ONG y la visibilización de las mujeres populares}

La década de los ochenta estuvo marcada por el conflicto armado interno que se desarrolló en el Perú durante los años de 1980 y 1992 y que tuvo como consecuencia alrededor de 69,000 peruanos y peruanas muertos o desaparecidos. Asimismo, fue un periodo de severa crisis económica, bajo el gobierno aprista de Alan García. En este contexto, el financiamiento de la cooperación internacional favoreció la consolidación de las ONGs en general y de las ONGs feministas.

Actoras en medio de dicha crisis y de la violencia política fueron las mujeres de sectores populares, tanto urbanas como rurales. Las primeras, como sobrevivientes del hambre, y las segundas, como sobrevivientes de la guerra.

Los partidos, específicamente los de izquierda, no consideraban en sus agendas las demandas feministas de las mujeres adscritas a ellos, por lo que, en 1982, "un número considerable de mujeres salimos de los partidos sin discusión, sin debate ideológico, sin pena ni gloria". ${ }^{14}$ La izquierda política había logrado hitos importantes por primera vez en la historia del país: luego de su participación en la Asamblea Constituyente de 1978, había ingresado al Congreso desde la vuelta a la democracia en 1980 y había ganado la alcaldía de Lima, en 1983. Sin embargo, ello no la hacía más permeable a la causa de las mujeres, construyendo así un nuevo modelo político más democrático.

La decisión de construir un movimiento feminista independiente de otras fuerzas sociales surge en el Segundo Encuentro Feminista Latinoamericano y del Caribe, realizado en Lima en el año de 1983, dando lugar así a la consolidación de organizaciones feministas que fueron tomando liderazgo y protagonismo. La cerrazón de los espacios políticos tradicionales a los temas específicos de las mujeres y más aún a aquellos relativos al cuerpo, la reproducción y la sexualidad, así como el creciente apoyo de la cooperación internacional, también propiciaron la agrupación de feministas en ONGs.

Las ONGs tenían otra dinámica muy distinta a la de un movimiento social: había niveles jerárquicos a su interior, y no necesariamente estaban interesadas en cooptar a más participantes en una estructura horizontal; respondían a resultados esperados por sus

\footnotetext{
${ }^{11}$ Entrevista de junio 2013.

${ }^{12}$ Reconocida feminista, científica social, autora de Supermadre: women in politics (1979), y especialista en el trabajo doméstico de la mujer y de las trabajadoras del hogar en América Latina.

${ }^{13}$ Coeditorajunto a Carol Wolkowitz y Roslyn McCullagh de Of Marriage and the Market: Women's Subordination Internationally and its Lessons (1981).

${ }^{14}$ Victoria VILLANUEVA, 2004, p. 44.
} 
financiadores externos, fundamentalmente enmarcados en políticas públicas más que en procesos de cambio socioculturales, y desarrollaban una interacción de "asesoría" a las "poblaciones meta" de sus proyectos. En definitiva, el trabajo en y con las esferas del poder generaba tensiones al interior del movimiento feminista, lo que finalmente haría que en 1991 se decidiera disolver el Comité de Coordinación del Movimiento Feminista - existente desde 1986 - y optar por un modelo de organizaciones profesionalizadas. ${ }^{15}$

Las corrientes de pensamiento teórico feminista no llegaron a ser difundidas, ni tuvieron peso relevante para el feminismo peruano. El escaso número de sus participantes no era suficiente para dividirse en posiciones ideológicas. La cuestión no era si se estaba en uno u otro feminismo, sino: '¿militas o no militas?'. En realidad no era un feminismo teórico que se apoderara de las ideas europeas en boga explayadas por - Cixous, Kristeva o Irigaray, América Latina vivía otra realidad y resolvía pragmáticamente las demandas de las mujeres haciendo política a su manera.

\section{La tensión entre la apertura al Estado y el desarrollo del movimiento/s autónomo/s}

Durante los noventa discurrieron dos gobiernos de Alberto Fujimori (1990-1995 y 1995-2000). Con un contexto de crisis política y económica, Fujimori emprendió un proyecto modernizador del país de cara al país y al mercado internacional, que al menos funcionó los cinco primeros años. En 1994, la postura oficial respecto de los derechos reproductivos en la Conferencia Internacional sobre Población y Desarrollo en El Cairo fue más bien conservadora y vigilante del no al aborto. En setiembre de 1995, el propio presidente Fujimori asistió a la Conferencia de Beijing. Según palabras de Fujimori, Beijing significó un cambio sustancial en sus políticas y en efecto, hacia fines de 1995, el Congreso de la República creó la Comisión de la Mujer, cuya primera presidenta fue la congresista Beatriz Merino. También en octubre de 1996, se creó al interior de la Defensoría del Pueblo la especializada en derechos de la mujer y finalmente, en octubre de 1996, se creó el Ministerio de Promoción de la mujer y del desarrollo humano (PROMUDEH). La institucionalización en el Estado de las causas de las mujeres se constituyó en un reto para las feministas: insistir en una radicalización de su discurso u optar por una negociación con el Estado. En ese sentido, iba a tener particular importancia la neutralización de la carga política del concepto de género que se transforma en un "recurso técnico", a decir de Maruja Barrig.

Durante este período una de las fundadoras de Flora Tristán, Narda Henríquez, impulsó el Diplomado de Estudios de Género en la Pontificia Universidad Católica, junto con profesores de la Facultad de Ciencias Sociales de esa universidad. ${ }^{16}$ Este proceso contribuyó a un nuevo perfil de activistas feministas. Hay que reconocer que la Academia pudo captar los conceptos aportados por el feminismo pero no al feminismo mismo, que continuamente es amenazado por su débil institucionalidad.

La captación de mujeres especialistas sobre el tema Mujer para las instancias públicas incidió en un tránsito de la acción política a la acción tecnocrática. Como fruto de la tensión entre pragmatismo y radicalismo, en 1996 y en 1997 surgen dos agrupaciones que se identificaban como mujeres en oposición al régimen fujimorista, el Movimiento Amplio de Mujeres y el MUDE. "La mayoría de las organizaciones no gubernamentales no participaron a nombre de sus propias instituciones. Por el contrario, las feministas individuales, pertenecientes o no a las ONG, se movilizaron en forma individual para unirse a estos

${ }^{15}$ Para algunas feministas entrevistadas, la multiplicación de estrategias y posiciones fue uno de los factores desencadenantes de la disolución del Comité de Coordinación del Movimiento Feminista.

${ }^{16}$ Gonzalo Portocarrero, Patricia Ruiz Bravo y Norma Fuller. 
movimientos."17 Solo a fines de la década, todas las mujeres se unieron en la crítica al gobierno al develarse con claridad la política estatal de metas de control poblacional a través de la anticoncepción quirúrgica voluntaria. El lema del MUDE, "Lo que no es bueno para la democracia no es bueno para las mujeres", expresaba la situación paradójica en que se encontraban las organizaciones feministas peruanas, en alianza con un Estado que aunque se manifestara antidemocrático, daba solución a las peticiones de las mujeres.

\section{El relanzamiento del feminismo a partir de la sexualidad (2003-a la fecha)}

Reconquistada nuevamente la democracia y logrado el equilibrio económico, esto no significó que el poder cambiara de manos en relación a quien lo tuvo en la época fujimorista. La institucionalidad continuó siendo precaria y la corrupción, luego del fujimorismo, se normalizó como una práctica en el aparato estatal. El Estado peruano dio, sin embargo, normas referidas a la igualdad de oportunidades (ley 28.983), a la protección contra la violencia familiar (ley 26.260), a la sanción del hostigamiento sexual (27.492), a las cuotas, al enfoque de género en los presupuestos (29.083), y al trabajo no remunerado en las cuentas nacionales (ley 29.700). Sin embargo, no existen resultados concretos en los aspectos más significativos para las mujeres como la violencia doméstica, la violencia sexual y el aborto.

Durante los años noventa, la pandemia del Sida hizo que el tema de la sexualidad se pusiera en boca de todos los países, y que los gobiernos tuvieran que producir políticas públicas que obligaron a hablar de sexualidad a los sectores de educación y salud. A esto se sumaron iniciativas de peso como la inversión de fondos de fundaciones como la Ford, que lanzó a nivel mundial, en 2001, el Diálogo Global en torno a la Sexualidad y los Derechos Humanos.

Dado el contexto, fueron los colectivos de derechos de la diversidad sexual los que volvieron a poner sobre el tapete las antiguas banderas de la radicalidad feminista. Se revalorizaron textos de autoras lesbianas feministas a la base de las nuevas vertientes de teóricas radicales de la sexualidad, en particular de la teoría queer. Bajo este enfoque se posiciona la crítica a la heteronormatividad y al esencialismo de las identidades. Sin embargo, se plantean debates sobre el continuar o no en la defensa de las identidades cuando estas sirven de indicadores en una situación donde la condición de la mujer aún no ha alcanzado un mínimo aceptable. El feminismo, sin embargo, no es una militancia que muchas mujeres jóvenes acepten, quizás porque identifican un solo feminismo como el institucional expresado por las ONGs.

\section{Aproximaciones finales}

Uno de los desafíos del feminismo peruano es cómo dar respuesta al contexto de cambios sociales, políticos y económicos que se da en la sociedad peruana. Una sociedad sin partidos políticos, sino, más bien, frentes electorales. La despolitización de la sociedad, producto de un fenómeno que ocurre a nivel mundial, la crisis de la política, unida a la penetración de la corrupción, el incremento del poder de los grupos fácticos que rigen el capital económico y el capital simbólico, la fragmentación e individualismo consumista, son todos aspectos de la realidad que plantean un contexto adverso a cualquier movimiento que reivindique lo político y la exigencia de derechos e igualdad de oportunidades.

17 Stéphanie ROUSSEAU, 2012, p. 109. 
En otro plano, jóvenes activistas, provenientes en su mayor parte del espacio universitario, se reivindiquen o no como feministas, llevan adelante banderas en relación a la sexualidad y al replanteamiento de los géneros. Se trata ya no solo de mujeres, sino de hombres y mujeres jóvenes, cuestionadores también de la problemática de género.

El feminismo peruano en este milenio también ha empezado el diálogo con otros movimientos, como el indígena. En el Perú, la categoría de indígena fue reemplazada hace cuarenta años por la económica de 'campesino', en la creencia de no estigmatizar y salvar del racismo a dicha población. En la actualidad, y gracias a la influencia de movimientos internacionales, lo 'indígena' vuelve a cobrar peso y es reivindicado como tal, recuperando su dimensión cultural. Sin considerarse a sí mismo como un feminismo poscolonial - en tanto no ha gestado un discurso propio de grupos que se autodenominen feministas y al mismo tiempo aporten con sus actorías una interseccionalidad -, lleva una agenda indígena o afrodescendiente sin que sus voceras se consideren representantes de estos grupos. El propio movimiento feminista no es fuerte ni numeroso, y en sus integrantes junta a todas aquellas mujeres sin distinción de agenda. Como un movimiento social más del Perú, no escapa a la dinámica que afecta a los demás movimientos, y su futuro dependerá de lo que le depare la democracia nacional.

\section{Referencias}

BARRIG, Maruja. Los Discursos sobre la Mujer Andina desde los operadores de proyectos de Desarrollo Rural. 2004. Tesis (Magíster en Política Social con Mención en Gestión de Proyectos Sociales) - UNMSM, Lima.

. "La persistencia de la memoria. Feminismo y Estado en el Perú de los 90". In: PANFICHI, Aldo (Coord.). Sociedad Civil, Esfera Pública y Democratización en América Latina: Andes y Cono Sur. México: Pontificia Universidad Católica del Perú - Fondo de Cultura Económica, 2002. p. 578-609.

"Los malestares del feminismo latinoamericano: una nueva lectura". In: XXI REUNIÓN DE LA LATIN AMERICAN STUDIES ASSOCIATION, Chicago. Setiembre, 1998. p. 24-26.

"Democracia emergente y movimiento de mujeres". In: BALLÓN, Eduardo (Ed.). Movimientos sociales y democracia: la fundación de un nuevo orden. Lima: Desco, 1986. p. 143-183.

BURNS, Kathryn. "Más allá del 'esencial femenino': Los comienzos del feminismo peruano". Socialismo y participación, n. 22, p. 117-130, junio. 1983.

. Más allá del 'esencial femenino': Los comienzos del feminismo peruano. 1981. Tesis (Magíster Historia) - BA, Princeton University, New Jersey.

CARLESSI, Carolina. Feminismo, una cuestión de poder. Lima: Movimiento Manuela Ramos, 1995.

. "Grupos de autoconciencia: 'Teníamos entre manos asuntos políiticos...'” Revista Viva, n. 4, p. 21-24, mar. 1985.

COMISIÓN DE LA VERDAD Y RECONCILIACIÓN (CVR).Informe Final. Lima: La Comisión, 2003. Tomo VIII.

CONDORI, Marisol et al. Influencia de las ideas de Simone de Beauvoir en la producción de las revistas La Tortuga, Mujer y Sociedad y Viva, en la década de los ochenta. Monografía. Lima: Pontificia Universidad Católica del Perú, 2002.

GIANELLA, Gonzalo E. "¿Por qué tendría que haber sucedido de otro modo? Notas sobre esterilizaciones y genocidio en el Perú". Ciberayllu, febrero. 2014. Disponible en: <http:/ /www.andes.missouri.edu/andes/Comentario/GG_Esterilizaciones.html > . Acceso en: 20 enero 2014

644 Estudos Feministas, Florianópolis, 22(2): 637-645, maio-agosto/2014 
"LA MUJER Y EL PODER". Informe. Revista Viva, Set./Oct. 1986.

MUÑOZ, Fanni et al. "El género y las políticas públicas en el Perú". In: AMES, Patricia. Las Brechas Invisibles. Desafíos para una equidad de género en la educación. Lima: IEP, 2006.

ORVIG, Helen. "También antes hubo algo". In: SEMINARIO NACIONAL "25 AÑOS DE FEMINISMO EN EL PERÚ: HISTORIA, CONFLUENCIAS, PERSPECTIVAS". Lima: Flora Tristán, 2004. p. 18-23. PORTUGAL, Ana María. "Las primeras feministas ante la ley". Revista Viva, marzo 1985.

ROUSSEAU, Stéphanie. Mujeres y ciudadanía: las paradojas del neopopulismo en el Perú de los noventa. Lima: IEP, 2012.

SALA, Mariella. "Feminismo y elecciones en el Perú". Revista Viva, marzo. 1985.

TAMAYO, Giulia. Silencio y complicidad. Lima: Cladem, 1998.

TRAPASSO, Rosa Dominga. "30 años de feminismo en el Perú". Ponencia del Encuentro Nacional de Mujeres 1999. Disponible en: <http://www.mamfundacional.org/recursos/ 30Feminismo RosaDominga.pdf>. Acceso en: 21 enero 2014.

VARGAS VALENTE, Virginia. Cómo cambiar el mundo sin perdernos. El movimiento de mujeres en el Perú y América Latina. Lima: Flora Tristán, 1991.

Feminismos en América Latina: su aporte a la política y a la democracia. Lima: Flora Tristán, PDTG y UNMSM, 2008.

El movimiento feminista en el horizonte democrático peruano (décadas 19801990). Lima: Flora Tristán, 2006. . El aporte de la rebeldía de las mujeres. Lima: Flora Tristán, 1989.

VILLANUEVA, Victoria. "Feminismo: una práctica de acción política". In: SEMINARIO NACIONAL "25 AÑOS DE FEMINISMO EN EL PERÚ: HISTORIA, CONFLUENCIAS, PERSPECTIVAS", 2004. Lima: Flora Tristán, 2004.

VILLAVICENCIO, Maritza. Breve historia de las vertientes del movimiento de mujeres en el Perú. Lima: Flora Tristán, 1990. Documentos de Trabajo, n. 3. . Las raíces del movimiento de mujeres en el Perú: informe final. Lima: Flora Tristán, 1987.

“¿El feminismo de la conciliación?”. Revista Viva, marzo 1985.

TUESTA SOLDEVILLA, Fernando. "El voto femenino". Revista Caretas, n. 1485, 2012. Disponible en: <http://www.caretas.com.pe/1485/voto/voto.htm>. Acceso en: 20 enero 2014.

ZEGARRA, Margarita. María Jesús Alvarado: la construcción de una intelectual feminista en Lima, 1878-1915. 2011. Tesis (Magíster en Historia), Universidad Mayor de San Marcos, Lima.

[Recebido em fevereiro de 2014 e aceito para publicação em abril de 2014]

\section{A Outline on Peruvian Feminism/s: Facing Multiple Challenges}

This paper is about the developments of feminism in Peru since the struggle for women's suffrage as the starting point till the post-war, with the positioning of the female body as the center of a new manner of thinking the political. Feminism is shown to be a middle-class women's movement, which stemmed from governmental initiatives and with not much presence of European schools of feminist theoretical thought. On the contrary, it was a movement bound with leftist ideologies whose proposals were paradoxically never considered by leftist parties. In the current changing context, which began with Peru's democratization and its lack of state institutionality, feminism/s lacking an evident organizational capacity - faces different demands, being the ability to meet diverse emerging actors the most relevant challenge.

Key Words: Feminism; Women's Movement; Institutionality; Government; Democratization. 